\title{
Online Teaching Satisfaction amid the Covid-19 Pandemic: Evidence from a Vietnamese Higher Education Context
}

\author{
Thach Ngoc Pham ${ }^{1 *}$, Van Hong Nghiem ${ }^{2}$
}

${ }^{1}$ Board of Trustees, Hanoi University, Km9, Nguyen Trai Road, Hanoi, Vietnam

${ }^{2}$ Faculty of Japanese Studies, Hanoi University, Km 9, Nguyen Trai Road, Hanoi, Vietnam

*Corresponding author. Email: thachpn@ hanu.edu.vn

* (D) https://orcid.org/0000-0003-3472-6355

do) https://doi.org/10.54855/ijte.222119

The COVID-19 pandemic has forced most higher education institutions around the globe to move their teaching and learning to online modes. This has had enormous impacts on teachers, especially those with limited experience in online teaching. This study was conducted to identify significant predictors of teacher satisfaction and their live online teaching experience during the coronavirus pandemic in Vietnam. The study used a mixedmethods approach with exploratory factor analysis, multiple regression techniques, and thematic analytical strategies to analyze survey data from 206 Vietnamese university lecturers. The study results indicated that online interaction, support from the institution, technology-related issues, and students' online efficacy were the key factors affecting lecturer satisfaction. In addition, the study

Keywords: COVID19 , teacher satisfaction, higher education, Vietnam. results offer practical implications for educational managers in their long-term investment in online education in a developing country context.

\section{Introduction}

The coronavirus that emerged at the end of December 2019 caused an unprecedented phenomenon when students of all levels were forced to study online due to the suspension of in-person classes. While educational institutions in the developed regions might be better prepared for online teaching and learning, schools and universities in the developing world had to rely on free applications like Zoom and Google Workspace (formerly G Suite) to host online classes (Aguilera-Hermida et al., 2021). These make-shift digital lessons barely satisfied the needs of students and teachers because many had neither online learning nor online teaching experience.

Vietnam successfully implemented pandemic control through a zero-Covid policy at the beginning of the outbreaks. Nevertheless, like most countries, the country's robust measures affected people of all walks of life, especially teachers and students. In fact, the continuous waves of the coronavirus suspended the most important student examinations - the high school completion and university entrance exams. They also had the most extended lunar new year (called Tet) in its modern history. Most Vietnamese higher education institutions switched to online teaching and learning in confronting the pandemic. While a few universities were familiar with and prepared for this mode of lesson delivery, many had to hurriedly train their 
teachers and students in pedagogical and technical skills in order to sustain education (Pham \& Ho, 2020).

Prior to the pandemic, the country's Ministry of Education and Training (MOET) had issued policies and directions to encourage educational institutions to deliver online courses and services to their students and the public. The country's national television channel broadcasts distance courses in languages, general knowledge, life skills, and school subjects like mathematics, physics, and chemistry (MOETa, 2020). This television source was primarily used before July's entrance examination to universities in Vietnam. MOET also provided guidance on quality assurance of online learning, especially the official guidelines on quality assurance of online distance teaching (MOETb, 2020).

Nevertheless, due to the compulsory migration to online teaching and learning, many issues needed further investigation, including teacher satisfaction. This study was an attempt to explore the factors that influence Vietnamese lecturer satisfaction with live online teaching in a higher education context. It combined analyses of quantitative data (through an online survey) and qualitative data (through semi-structured interviews) to obtain a picture of the teachers' experiences and perceived satisfaction in performing the unprecedented mode of lesson delivery.

\section{Literature Review}

Teacher satisfaction is a complex issue, and components of teacher satisfaction need to be investigated as they play an essential role in promoting online interaction through scaffolding strategies and, most importantly, ensuring the quality of online education (Cho \& Cho, 2016). Teachers are more satisfied when they believe that students can achieve better learning outcomes, the foundation of online learning satisfaction (Allen \& Seaman, 2015). Teacher satisfaction in online learning is dependent on several factors, including their perceptions about the effectiveness of online teaching, support from institutions, online interaction, and many other academic and non-academic issues (Daniel, 2020; Kuo et al., 2014; Pakkad, 2021; Sobaih, 2021). During the pandemic, teachers played a key role in innovating and designing flexible programs to suit live online teaching and learning (Dhawan, 2020; Teng \& Wu, 2021).

Research on teacher experience in online teaching is often based on the technology acceptance model (TAM) created by Davis (1989). This model predicts users', including teachers' perceptions and willingness to adopt online teaching. However, due to the coronavirus, most teachers had to use available applications for their online work and changed their mindset for the betterment of their students (Shenoy et al., 2020). As a result, these teachers had fewer options as they were forced to adapt to the "new normal" of education (Moralista \& Oducado, 2020). Therefore, institutions had to invest in teacher training and technical support of different types, including skills in the use of applications and platforms, Internet connectivity, and even feelings of sadness or anxiety (Moralista \& Oducado, 2020; Talidong \& Toquero, 2020).

Confronting with new forms of teaching and lacking prior experience and alternative solutions, many teachers found it hard to come up with effective strategies to deliver online lessons, especially senior ones (Cataudella et al., 2021). Their challenges were numerous, including lack of technical support from their institutions, adoption to online teaching, and managing personal life with work life and mental stress (Kakkad, 2021; Hermanto \& Srimulyani, 2021; Teng \& $\mathrm{Wu}, 2021)$. As the teaching and learning environment was new to many teachers, their biggest concern was the learners' interaction with content, peers, and instructors. 
When being in the live online lessons, it was unclear how much learners gained from the teachers' live delivery of the content and the pre-uploaded materials. Due to the emergency of online teaching, most lecturers just used online meeting platforms like Zoom or Google Workspace to deliver the lesson content and upload reading materials designed for conventional lessons (Baber 2020). The live presentation of lesson content and provision of reading materials tended to be one-way and unsystematic (Hermanto \& Srimulyani, 2021). Hence, the quality of learning from these materials could have been below teachers' expectations.

Regarding learners' interaction with teachers and peers, the commonly used online meeting applications (e.g., Zoom) allowed the students to interact with each other in breakout rooms. However, there were numerous unanswered questions about the quality of their discussions. Students might not have been used to this way of online discussion before and faced numerous problems such as the lack of direct communication and human touch, privacy, and account security (Adnan \& Anwar, 2020; Dhawan, 2020; Sobaih et al., 2021). Some teachers used social media groups such as Facebook or WhatsApp to promote more interaction with students, adding to the already heavy workload. In addition, due to the emergency, not all teachers were trained in instructional design to foster live interaction between the teachers and students as well as among the students, meeting the need for different learning styles (Maheshwari, 2021; Sobaih et al., 2021). The new (online) teaching environment did cause considerable ambiguity and complication to the teachers (

Teacher satisfaction in online teaching is also closely related to their students. Researchers have established a positive correlation between faculty satisfaction and student performance and engagement (Kuo et al., 2014; Shenoy et al., 2020). Teachers are more encouraged when they know their online teaching is better than traditional sessions and vice versa (Hermanto \& Srimulyani, 2021; Shenoy et al., 2020). Barriers to student satisfaction during the pandemic included technical and security problems when using Zoom or Google Meet (Nambiar, 2020). Many students even experienced mental and physical health issues because of the lockdown and social distancing rules (Baloran, 2020; Nambiar, 2020).

In summary, teacher satisfaction in online learning depends on several factors, which can be classified into those related to institutions, students, and teachers themselves. Teachers were forced to use online meeting applications during the pandemic to deliver online lessons. While some were familiar with this mode of teaching, others found it challenging to navigate. There have been some studies in the world and Vietnam on this issue, but there has not been an agreement on the key factors that affect Vietnamese university lecturers. Hence, this study aims to add to what has already been known and is still missing in the literature about compulsory online teaching in Vietnam, where technological development is not as advanced as in developed countries, especially the use of copyrighted applications.

The current study was guided by a conceptual framework that includes the key factors influencing teacher satisfaction with online teaching (Allen \& Seaman, 2015; Cho \& Cho, 2016). These factors were broken into teacher, student-, and institution-related issues. Figure 1 shows the conceptual framework of the study. 


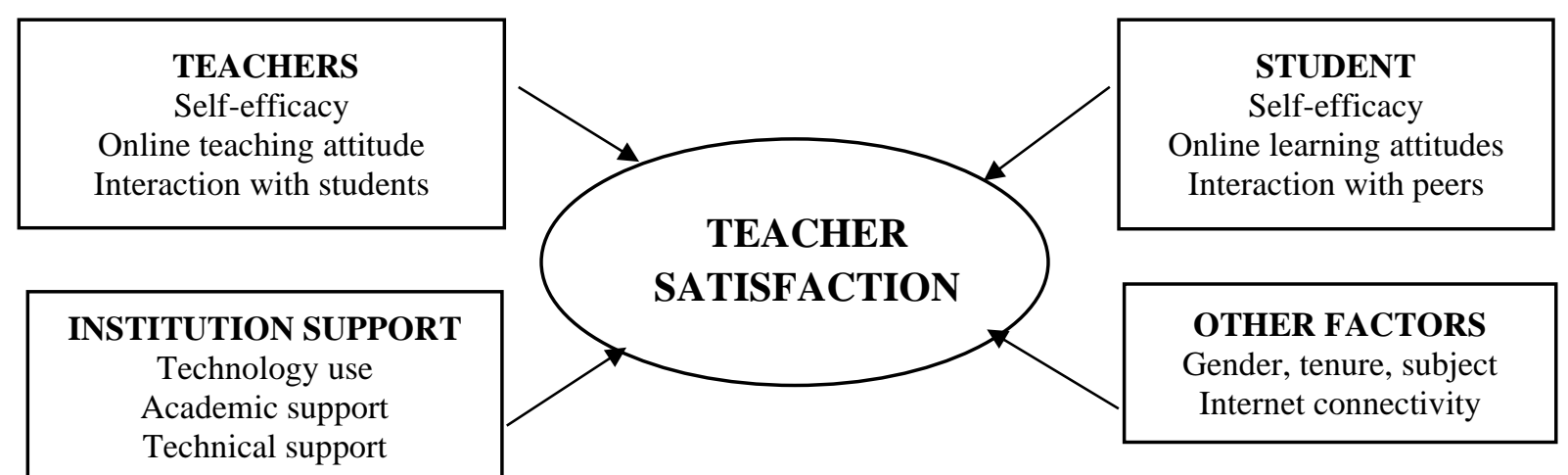

Figure 1. Study's conceptual framework

To fulfil the purpose of the study, the following two research questions were developed:

Question 1. Which factors influenced university teachers' satisfaction during the live online teaching due to Covid-19 in Vietnam?

Question 2. What were the teachers' experiences during the live online teaching due to Covid-19 in Vietnam?

\section{Method}

\subsection{Participants and online courses}

Purposive sampling was used to approach participants. Research participants included 206 teachers from a Vietnamese university. Participants belonged to two groups of teachers. The first group taught foreign languages like English, Chinese, and Japanese, while the second group taught business administration, information technology, and banking and finance in English and French. Participants began teaching online in late February 2020 when Vietnam banned large gatherings and exercised social distancing measures. Table 1 presents the demographic characteristics of the participants.

Table 1.

Participants' demographic characteristics

\begin{tabular}{|r|c|c|}
\hline Information & Number & Percentage \\
\hline Fender & & 85.4 \\
\hline Male & 176 & 14.6 \\
\hline Online teaching experience & 30 & 28.6 \\
\hline Yes & 59 & 71.4 \\
\hline No & 147 & 62.6 \\
\hline Peaching subject & & 37.4 \\
\hline Practice-based & 129 & 20.4 \\
\hline Theaching tenure (years) & 77 & 29.6 \\
\hline Under 5 & & 31.6 \\
\hline $6-10$ & 61 & 15.5 \\
\hline $11-15$ & 65 & 2.9 \\
\hline On-20 & 32 & 10.2 \\
\hline Internet connectivity 20 & 6 & 89.8 \\
\hline Unstable & 21 & \\
\hline Stable & 183 & \\
\hline
\end{tabular}


There were a lot more female than male teachers at the participating university ( 85.4 versus 14.6), and the majority of them (71.4) had not experienced online teaching before the outbreak of Covid-19. As a language university, more teachers taught practice-based subjects (e.g., language skills, interpreting and translation) than theory-based ones (like the history of the Vietnamese Communist Party, foreign literature, macroeconomics). More than half of the teachers had 6-15 years of teaching experience, but less than $3 \%$ had been at the university for more than 20 years. A vast majority of them (89.8\%) also enjoyed stable Internet connectivity during the online teaching time. Teachers stayed at home in Hanoi, the capital city, or their hometowns to deliver online lessons via Zoom or Google Workspace. Except for physical education, lessons were taught online for all language practice courses, interpreting and translation (for language majors), and specialized courses (for non-language majors).

\subsection{The survey instrument and data collection}

A questionnaire was developed with relevant demographic variables and factors influencing online teaching satisfaction in a 5-point Likert scale (strongly disagree, disagree, neutral, agree, and strongly agree). The questionnaire development process involved two stages. In stage 1, questionnaires from past studies were documented, translated into Vietnamese, and scrutinized. An expert judgment session was organized to ensure the instrument's content validity. Eight teachers involved in online teaching during the pandemic were invited to read the questions and comment on whether the questions were appropriate for this study. Modifications, including item deletions or additions and wording changes, assured question suitability. In stage 2, the questionnaire was piloted on ten more teachers who were teaching online at the time of the pandemic (these teachers were excluded from participating in this study). The questionnaire contained both closed- and open-ended items. The Cronbach's coefficient alpha values, calculated based on the pilot sample of this study, indicated that the developed items were reliable (0.93).

All online teachers at the institution were emailed an invitation to participate in the study. About 400 teachers received information about the study and a link to the online experience and satisfaction survey hosted in Google Forms. To increase the response rate, reminders were also emailed to the online teachers. After ten days, 217 responses were received from the teachers, accounting for $54 \%$ of the targeted teachers. However, after cleaning the data by deleting invalid responses, only 206 were usable for analysis, accounting for $52 \%$ of the total number of the targeted teachers.

After the initial analysis of quantitative data, the researchers developed semi-structured interview questions and conducted face-to-face interviews with five teachers from different faculties of the university on a voluntary basis. This process aimed to explore, among other things, teachers' opinions about the results of quantitative data analysis. The interviews were conducted when the teachers resumed their offline teaching thanks to the ease of Covid-19 in Vietnam at the time. Interviewed participants' anonymity was protected by using pseudonyms (Lahman et al., 2015). The researchers also exploited answers to the open-ended question. Around $30 \%$ of the survey participants provided additional comments in the questionnaire.

\subsection{Data analysis}

The quantitative data were analyzed using both simple descriptive statistics like frequency analysis and inferential statistics with the help of Statistical Package for Social Sciences (SPSS), version 22. Descriptive analyses were conducted to present each participant's basic information; an exploratory factor analysis (EFA) was performed to investigate factors influencing teacher satisfaction in online teaching. EFA was used to reduce a large number of variables in the 
questionnaire down to smaller groups of factors. After the groups of factors were identified, correlation analysis was performed to explore the relationships among the groups of factors. Then, multiple regression analysis was conducted to find the influence of these groups of factors on teacher satisfaction. In addition, t-test analyses were performed to explore the differences and effects of teachers' backgrounds (i.e., gender, online teaching experience, teaching subjects, and Internet connectivity) on their overall satisfaction with online teaching.

Qualitative data were processed using content analysis (Miles et al., 2014). A triangulation technique was adopted in which the quantitative results were supported and explained by findings from the qualitative data (Teddlie \& Tashakkori, 2009). The analytical analyses mentioned above were usually employed in past studies about online teaching and learning satisfaction (Hermanto \& Srimulyani, 2021; Kuo et al., 2014; Zaili et al., 2019). The following sections present key findings of the analysis.

\section{Results}

\subsection{Results of quantitative data analysis \\ 4.1.1. Exploratory factor analysis}

An EFA using SPSS was conducted in order to answer the first research question about the factors influencing university teachers' satisfaction during the live online teaching due to Covid-19 in Vietnam. The 22 items that influenced teacher satisfaction were subjected to this analysis. Prior to performing the EFA, the suitability of data for factor analysis was assessed. Inspection of the correlation matrix revealed the presence of 14 coefficients of 0.3 and above. The Kaiser-Meyer-Olkin (KMO) value was 0.718, exceeding the recommended value of 0.6; Bartlett's Test of Sphericity indicated statistical significance. These findings support the factorability of the correlation matrix. EFA revealed the presence of four components with eigenvalues exceeding 1, explaining $28.99 \%, 21.35 \%, 13.92 \%$, and $9.39 \%$ of the variance, respectively.

Oblimin rotation aided in the interpretation of these four components. The rotated solution revealed the presence of a simple structure with four components, demonstrating several strong loadings and most variables loading substantially on only one component. The interpretation of the four components was consistent with a study on factors influencing teacher satisfaction in online courses with high loadings on components like technology, institution support, and the online course. The Cronbach alpha values for the retained items were over 0.70, suggesting acceptable internal consistency. A summary of factor loadings is provided in Table 2. 
Table 2.

Rotated factor loadings for constructs

\begin{tabular}{|c|c|c|c|c|c|c|}
\hline \multirow[t]{2}{*}{ Factor } & \multirow[t]{2}{*}{ Item } & \multicolumn{4}{|c|}{ Component } & \multirow{2}{*}{$\begin{array}{c}\text { Cronbach } \\
\text { alpha }\end{array}$} \\
\hline & & 1 & 2 & 3 & 4 & \\
\hline \multirow{4}{*}{$\begin{array}{l}\text { Online } \\
\text { interaction }\end{array}$} & $\begin{array}{l}\text { Frequency of learner-learner } \\
\text { interaction }\end{array}$ & .915 & & & & .777 \\
\hline & $\begin{array}{l}\text { The efficiency of learner-learner } \\
\text { interaction }\end{array}$ & .890 & & & & .775 \\
\hline & $\begin{array}{l}\text { The efficiency of instructor-learner } \\
\text { interaction }\end{array}$ & .772 & & & & .778 \\
\hline & $\begin{array}{l}\text { Frequency of instructor-learner } \\
\text { interaction }\end{array}$ & .763 & & & & .778 \\
\hline \multirow{5}{*}{$\begin{array}{l}\text { Learner } \\
\text { efficacy }\end{array}$} & Learner computer skills & & .888 & & & .795 \\
\hline & Learner Internet skills & & .846 & & & .795 \\
\hline & Learner language competence & & .696 & & & .796 \\
\hline & Learner autonomy & & .692 & & & .793 \\
\hline & $\begin{array}{l}\text { Learner attitude towards online } \\
\text { learning }\end{array}$ & & .686 & & & .792 \\
\hline \multirow{3}{*}{$\begin{array}{l}\text { Institution } \\
\text { support }\end{array}$} & $\begin{array}{l}\text { Academic support from the } \\
\text { university }\end{array}$ & & & .924 & & .772 \\
\hline & $\begin{array}{l}\text { Technical support from the } \\
\text { university }\end{array}$ & & & .921 & & .784 \\
\hline & Academic support from faculty & & & .887 & & .783 \\
\hline \multirow{2}{*}{ Technology } & Instructor technological skills & & & & .821 & .785 \\
\hline & Online learning application & & & & .743 & .789 \\
\hline
\end{tabular}

Data in Table 2 shows that the factor loadings were on four components: online interaction, learner efficacy, institution support and technology, reflectively. These four components explained $73.66 \%$ of the variance. Data from Table 2 reveals that the first component concerned factors were related to online interaction, specifically frequency and efficiency of interaction between the teachers and students and among the students. The second component was related to learner efficacy: their computer and Internet skills as well as learning autonomy and attitude towards online learning. The third component was about institution support, both academic and technical. The fourth component concerned the technology, specifically applications used and the teachers' skills in using them for online teaching. The highest loading was on academic support from the university (0.924), and the lowest was on the learners' attitude towards online learning (0.686).

\subsubsection{Correlation}

Table 3.

Correlation between variables

\begin{tabular}{|c|c|c|c|c|c|}
\hline & 1 & 2 & 3 & 4 & 5 \\
\hline 1. Interaction & 1 & .012 & $.293^{* *}$ & $.394^{* *}$ & $.614^{* *}$ \\
\hline 2. Learner efficacy & & 1 & .057 & .117 & -.098 \\
\hline 3. Institution support & & & 1 & $.245^{* *}$ & $.366^{* *}$ \\
\hline 4. Technology & & & & 1 & $.478^{* *}$ \\
\hline 5. Satisfaction & & & & & 1 \\
\hline
\end{tabular}

**. Correlation is significant at the 0.01 level (2-tailed). 
Table 3 shows the Pearson correlation coefficients between the variables. Three components (interaction, institution support and technology) were positively related to satisfaction ( $\mathrm{p}<$ 0.01), but learner efficacy (e.g., computer, Internet skills and autonomy) was not. Data in Table 2 indicates that interaction had the most significant correlation $(r=0.614)$ with teacher interaction, followed by technology $(\mathrm{r}=0,478)$, whereas institution support recorded the smallest association with teacher satisfaction $(\mathrm{r}=0.366)$. Correlations between the independent variables were at small and medium levels (from 0.012 to 0.394 ).

\subsubsection{Regression}

A multiple regression analysis was performed to see how much the independent variables predicted teacher satisfaction. Before conducting regression analysis, the suitability of data was assessed. The distribution of the data showed no extreme outliers for the data set. The tests also showed that the variables met the assumption of normality, linearity, multicollinearity, and homoscedasticity (Pallant, 2011). After the entry of the four variables, the total variance explained by the model (adjusted R square) was 0.48 , which indicates that the model explains $48 \%$ of the variance.

Table 4.

Multiple regression of predictors of teacher satisfaction

\begin{tabular}{|l|c|c|c|c|c|}
\hline & Beta & $\mathrm{T}$ & Sig. & Tolerance & VIF \\
\hline (Constant) & & 3.470 & .001 & & \\
\hline 1. Interaction & .458 & 8.144 & .000 & .802 & 1.246 \\
\hline 2. Learner efficacy & -.145 & -2.854 & .005 & .984 & 1.017 \\
\hline 3. Institution support & .173 & 3.251 & .001 & .893 & 1.120 \\
\hline 4. Technology & .272 & 4.883 & .000 & .816 & 1.226 \\
\hline \multicolumn{4}{|l|}{ R square $=0.479 ; \mathrm{F}=48.19(4: 206)$ Sig. F $=0.000$} \\
\hline
\end{tabular}

Table 4 shows that all four components were significant predictors in explaining teacher satisfaction. Comparing the contribution of each independent variable, Table 4 shows that when the variance explained by all other variables in the model was controlled, interaction made the strongest positive contribution to explaining satisfaction $(\beta=0.46)$. Beta values for three other variables (technology, institution support, and learner efficacy) indicated smaller positive contributions of $0.27,0.17$, and -0.15 , respectively.

\subsubsection{T-test}

An independent sample t-test was conducted to explore if demographic characteristics (e.g., gender, prior online teaching experience) influenced teacher satisfaction. Table 5 shows that gender and prior online language teaching experience did not predict teacher satisfaction $(\mathrm{p}=$ 0.41 and 0.74 , respectively). There was no significant difference in scores for females $(\mathrm{M}=$ $3.53, \mathrm{SD}=0.59)$ and males $(\mathrm{M}=3.43, \mathrm{SD}=0.73 ; \mathrm{t}(206)=0.83, \mathrm{p}=0.41$, two-tailed $)$ in online teaching satisfaction. Similarly, there was no significant difference in scores for teachers who had no prior experience in online language teaching $(\mathrm{M}=3.51, \mathrm{SD}=0.62)$ and those with prior experience $(\mathrm{M}=3.54, \mathrm{SD}=0.60 ; \mathrm{t}(206)=-0.34, \mathrm{p}=0.74$, two-tailed $)$. However, the teaching subjects did affect satisfaction. Those who taught theory-based subjects $(\mathrm{M}=3.64)$ were more satisfied than those who taught practice-based subjects $(\mathrm{M}=3.45)$. The magnitude of the difference, nevertheless, was small $($ eta $=0.02)$. Similarly, teachers with better Internet connectivity $(M=3.56)$ were more satisfied than those with weak connectivity $(M=3.19)$. Again, the magnitude of the difference was small (eta $=0.03$ ). 
Table 5.

Effects of demographic characteristics on teacher satisfaction

\begin{tabular}{|c|c|c|c|c|c|c|c|c|}
\hline & \multicolumn{8}{|c|}{ Online teaching satisfaction } \\
\hline & & Levene & $\mathrm{N}$ & $\mathrm{M}$ & SD & $\mathrm{t}$ & Sig. & Eta \\
\hline \multirow{2}{*}{ Gender } & Female & \multirow{2}{*}{0.080} & 176 & 3.53 & 0.594 & \multirow{2}{*}{0.829} & \multirow{2}{*}{0.408} & \\
\hline & Male & & 30 & 3.43 & 0.728 & & & \\
\hline \multirow{2}{*}{$\begin{array}{l}\text { Prior online } \\
\text { teaching } \\
\text { experience }\end{array}$} & No & \multirow{2}{*}{0.569} & 147 & 3.51 & 0.623 & \multirow{2}{*}{-0.339} & \multirow{2}{*}{0.735} & \\
\hline & Yes & & 59 & 3.54 & 0.597 & & & \\
\hline \multirow{2}{*}{$\begin{array}{l}\text { Teaching } \\
\text { subjects }\end{array}$} & $\begin{array}{r}\text { Practice- } \\
\text { based }\end{array}$ & \multirow{2}{*}{0.439} & 129 & 3.45 & 0.612 & \multirow{2}{*}{-2.128} & \multirow{2}{*}{0.035} & \multirow{2}{*}{0.02} \\
\hline & $\begin{array}{r}\text { Theory- } \\
\text { based }\end{array}$ & & 77 & 3.64 & 0.605 & & & \\
\hline \multirow{2}{*}{$\begin{array}{l}\text { Internet } \\
\text { connectivity }\end{array}$} & Not stable & \multirow{2}{*}{1.34} & 21 & 3.19 & 0.602 & \multirow{2}{*}{2.63} & \multirow{2}{*}{0.009} & \multirow{2}{*}{0.03} \\
\hline & Stable & & 185 & 3.56 & 0.606 & & & \\
\hline
\end{tabular}

The study also utilized the ANOVA technique to explore differences among groups of teachers with different tenures (under five years, 6-10 years, etc.) and online teaching satisfaction. The results of the analyses did not show significant differences $(p>0.05)$. In summary, only two factors were significant predictors of teacher online teaching satisfaction among the controlling variables: the subjects (theory or practice) and Internet connectivity.

\subsection{Triangulation of quantitative and qualitative results}

In order to answer the second research question about the lecturers' experience in the live online teaching amid Covid-19, the researchers determined the answers to the open-ended survey question and semi-structured interviews. The following section presents the triangulation of the results of analyzing two datasets related to the lecturers' compulsory online teaching experience during Covid-19.

First, the quantitative analysis revealed that the usefulness of teacher-student and studentstudent interaction was a significant predictor of lecturer satisfaction $(\beta=0.458)$. In the interviews, all the interviewed teachers confirmed this finding, adding that:

Interaction between teachers and students is always decisive in both online and offline environments. (HNUGV05)

Online interaction had some advantages over offline interactions, revealing that:

... this interaction was not interrupted by student-student interaction. (HNUGV901)

Many students were more confident in giving answers by tapping on the chat windows. In fact, students were often shy in an offline context. The online lessons were also interconnected with other resources so both teachers and students could read and comment via the chat window. Online interaction in practice-based lessons increased, which encouraged the first-year students to be more active in establishing a habit of chatting with teachers online.

However, in the survey, some teachers commented that the nature of online teaching (sitting for a long time in front of the computer) limited their interaction with students in comparison with an offline context. One teacher stated:

It is noisy if all students turn on their microphones at the same time. (HNUGV82)

Another teacher wrote that: 
Teachers have to prepare carefully for their online lessons and teach for the whole day with a lot more workload. Their interaction with the students becomes limited. (HNUGV 32)

Technical constraints like poor microphone sound or blurred facial expressions resulted in lowquality teacher-student interaction. However, it is interesting that many students reported microphone malfunctions only when requested to speak.

The second and third significant predictors of online teaching satisfaction were the technology, specifically applications used for online teaching and teacher skills in using them $(\beta=0.272)$ and institution support $(\beta=0.17)$. Some teachers answered that these skills were essential regarding the teachers' technical skills in operating Zoom and Google Meets. They were satisfied with both the application and training provided to them before and during the online teaching period. One interviewee stated:

Teachers with good Internet self-efficacy can search for information and support their students to the best of their ability. On the other hand, those with weaker technical abilities find it hard to deliver a lesson effectively. (HNUGV901)

In answers to the open-ended question, the participants appreciated the support:

I think the applications were very useful, and different departments collaborated well in supporting teachers. (HNUGV74)

I hope to get more support from the university, especially Internet connectivity (ID30)

... financial support. (HNUGV11)

Interestingly, the quantitative data findings revealed that student self-efficacy was the weakest predictor of teacher satisfaction $(\beta=0.145)$. Indeed, teachers mentioned a few students' technical problems during the lesson, including the failure of a microphone:

... when the teachers asked them to practice speaking, some did not have a microphone or had a malfunctioning one. (HNUGV905)

Another interviewee noted:

During the lesson, many students accidentally turned on their microphones, which caused much noise. Other students did not know where the noise was coming from either. How could I teach in that situation? (HNUGV903)

In answers to the open-ended question, many teachers mentioned the need to provide student support for Internet connectivity:

Students need to be supported with stable Internet connectivity. (HNUGV69)

Another teacher elaborated:

Sometimes students had problems with Internet connectivity, resulting in their failure to attend the lesson. So, for online teaching to be effective, it is necessary to pay attention to teachers' facilities and students' Internet connectivity. (HNUGV39)

After reviewing participants' answers to this open-ended question, it was found that they might have mistaken students' Internet self-efficacy with Internet connectivity. This was confirmed in the results of the t-test (see Table 5), which indicated that more stable connectivity resulted in more satisfied teachers. This was complemented in the interviews whereby the teachers stated that Internet connectivity had a decisive impact on the quality of learning outcomes and student motivation. Some stressed: 
Internet connectivity needs to be stable for good communication, studying content, providing feedback, and sharing opinions from students. (HNUGV902)

Some students were kicked out five to six times during a one-and-one-half hour lesson; hence, they were distraught. Some of them ceased their attendance after experiencing technical errors. (HNUGV901)

Finally, the result of the t-test indicated that teachers' prior experience in online teaching did not predict their satisfaction during the pandemic's emergency teaching format (see Table 5). Indeed, online teaching was an emergency response to the coronavirus; therefore, teachers had to be familiar with online teaching and had to adapt to new teaching environments. Some of the teachers commented on this phenomenon:

I think this is understandable because we had to teach online due to COVID-19. (HNUGV905)

I think this is logical because we have only been teaching offline in Vietnam. We have only just begun to apply online teaching, and it is a good beginning. (HNUGV902)

... offline teaching has already met students' needs, or there are differences among teachers. For example, I am not a fan of technology, so I have not taught online. This time, it was a must, no matter if I liked it or not. (HNUGV904)

One teacher noted that online teaching via online meeting platforms was, in fact, not a fully functional LMS. Therefore, the technical skills needed to deliver the online lessons were not complicated. In answers to open-ended questions and interviews, most participants valued the technical support received during the online teaching period, especially the less experienced teachers.

I think teachers with weak technical skills and low Internet self-efficacy will find it easier and have more confidence if they get online support from someone. The more satisfied they are, the better their lessons. (HNUGV901)

The department and university were ready to listen and respond instantly to any problems faced by the teachers. (HNUGV905)

One interviewee used an interesting metaphor to describe this support:

It is like when you are drowning and receive a lifeboat from someone. You can get to shore. (HNUGV903)

The analyses of quantitative and qualitative data in this study reveal that factors impacting satisfaction with online teaching during the pandemic were related to teachers' interactions with students, technical performance, student behaviour, and support from the institution. The study results show that teachers can adapt when forced to teach online. However, the teachers noted that blended learning models ensure the quality of learning outcomes.

I think a combination of online and offline learning will be more flexible and effective because each mode has its own advantages. (HNUGV76)

In the future, online teaching should be blended with offline at [name of institution], especially for theory-based courses. (HNUGV61)

... combine online with offline learning, even in non-pandemic situations. (HNUGV37) 
As mentioned in this study, online teaching during the coronavirus pandemic occurred through live video conferencing applications. An investment in a fully operational LMS will ensure the long-term effects of online learning.

\section{Discussion of results}

The current study aimed to explore the factors that influenced university lecturers' satisfaction in a live online learning context at a Vietnamese university with the use of a mixed-methods approach built on data collected from a survey and interviews with 206 university lecturers. The study results indicated that online interaction had the strongest impact, followed by institution support and technology-related issues (lecturers' technical skills and applications used). Internet connectivity and the subject taught (theory or practice-based) also had an influence on teacher satisfaction. In what follows, the study results will be compared to the findings of the previous studies.

First, during live online teaching, interactions (learner-teacher, learner-learner, learner-content) were crucial in teacher satisfaction. This result is consistent with other studies, suggesting that teacher-student interaction plays a vital role in online learning (Kuo et al., 2014; Lumsden, 2017). However, other studies do not support the current result that noted teachers' concerns about interactions with students in an online environment (Hermanto \& Srimulyani, 2021; Maheshwari, 2021; Moralista \& Oducado, 2020). In this regard, earlier research revealed that teachers played multiple roles in promoting interpersonal interaction in an online environment through acts like regularly posting messages and announcements encouraging students to share problems and concerns through the use of different social media (Cho \& Cho, 2016; Sobaih et al., 2021).

However, due to the emergency, many teachers were not trained in these pedagogical skills. It was also clear from the current study results that teachers had many difficulties connecting to their students during the live online learning amid Covid-19. This finding is in agreement with the results of a study by Sobaih et al. (2021), which showed that several barriers were identified in teacher-learner interaction. Due to technical and pedagogical constraints, the teachers were not fully trained to promote online interaction with the students and redesign teaching materials to suit the online environment. This resulted in a one-way interaction pattern (Baber, 2020; Hermanto \& Srimulyani, 2021). Teachers' concerns about the limited interactions were particularly relevant because in language learning, students' interactions with peers, both verbally and non-verbally, play an essential role in their developing language proficiency (Pham, 2022).

Second, in the current study, technology had a statistical influence on teacher satisfaction, which supports the findings of past research indicating that teachers tend to be more satisfied with online teaching if their technical skills are good and vice versa (Ayu \& Pratiwi, 2021; Shenoy et al., 2020). Teachers in this study managed to conduct the live online lessons despite their lack of prior experience in online teaching. This finding agrees with the results of earlier studies on teachers' perceptions of online teaching both in a normal situation and during the Covid-19 pandemic period, which revealed that teachers could adapt to an online environment despite their lack of prior experience (Kakkad, 2021; Hermanto \& Srimulyani, 2021; Shenoy et al., 2020; Wingo et al., 2017. Nonetheless, the current study participants were concerned about the students' technical difficulties (i.e., Internet connectivity, a broken microphone [intentionally or unintentionally]). This result is supported by findings of previous studies, which posited that technical skills, access to equipment, and abilities to use technology were 
teachers' concerns in online teaching (Kakkad, 2021; Dhawan, 2020; Sobaih et al., 2021; Teng $\& \mathrm{Wu}, 2021)$.

Third, it was revealed from this study that supports from institutions had a substantial impact on teacher satisfaction. This result agrees with the findings of some other researchers, which indicated that support from institutions plays a critical role in teacher satisfaction and the success of an online course, especially the provision of technical and pedagogical training (Cataudella et al., 2021; Dhawan, 2020; Wingo et al., 2017). The results of this study also corroborate the ideas of previous research, which stated that teachers value support from institutions even if they must teach online and endure more workload due to subjective reasons (Kakkad, 2021; Lapitan et al., 2021).

The result of the t-test indicated that gender and prior experience in online teaching did not predict teacher satisfaction during the pandemic's emergency teaching format. Indeed, online teaching was an emergency response to the coronavirus; therefore, all teachers had to be familiar with online teaching and adapt to new teaching environments. This finding partially agrees with the results of a study by Kakkad (2021), which indicated a significant difference between gender and satisfaction with online teaching (p.35). However, the above finding contradicts the results of a study by Cataudella et al. (2021), revealing that teachers with noprior online teaching experience failed to find active solutions to online teaching problems.

\section{Conclusion, Implications and Limitations}

The methodological approach in this study is based on quantitative and qualitative data gathered from a survey and semi-structured interviews with teachers who taught online during the coronavirus pandemic in Vietnam. Qualitative findings supported results from the quantitative analysis. The study revealed three main groups of factors that influenced teacher satisfaction: (1) learner-learner and learner-instructor interactions; (2) technology; and (3) support from the institution. While teachers appreciated the advantages of online teaching, this study found that they believed blended learning ensured higher-quality learning outcomes.

The coronavirus pandemic has caused negative impacts on all facets of our lives. It has also created opportunities for countries to embrace digital transformations in education and training (Minh, 2020; MOETb, 2020). In this context, the findings from this study add a few implications to the current practice of online teaching and learning in Vietnam. First, when implementing an online learning program, attention should be paid to the usefulness or effectiveness of interactions between teachers and students. While online interaction differs from its offline classroom counterpart, teachers continue to facilitate the process. In this regard, teachers should be trained to design suitable learning materials and prompt students to think and respond effectively. Blended learning should be implemented instead of relying on the emergency delivery of content as experienced during the coronavirus pandemic. In addition, the synchronous interaction time should be designated for questions and answers. These efforts will promote the self-regulation of the learner, which was only at a medium level (Luu, 2022).

Second, all universities in Vietnam rolled out online learning during the pandemic to sustain education. However, teachers, students, and institutions faced many problems, including technical constraints, due to the emergency nature of the work. At the same time, Internet connectivity throughout Vietnam and the technological limitations of the applications created a challenging online learning experience (Maheshwari, 2021). For long-term delivery, institutions must incorporate advanced technologies and updated educational tools into their 
formal curriculum and implement a blended learning model to ensure the quality of teaching and learning (Daniel, 2020; Hermanto \& Srimulyani, 2021; Lapitan et al., 2021).

Third, institutions must consider several factors when organizing their online teaching and learning environment. Institutions must select online platforms, applications, and training programs that are familiar to teachers. Some teachers, especially those with more exposure to technology, may find it easier to use an interface, move between Web pages, and organize online groups or pair-work. On the other hand, teachers with limited experience in technology may struggle with the new platforms. Hence, teachers will appreciate professional development opportunities and/or continuous training and support from the institutions, especially online teaching experience (Cataudella et al., 2021; Hermanto \& Srimulyani, 2021; Ngo, 2021).

The findings in this study are not free of limitations. First, the data in this study came from teachers. To see a fuller picture of online teaching and learning during this historic pandemic, future research should include an in-depth investigation of the perception of learners, teachers, and education administrators. Second, although the number of participants in this study was relatively large (206), it was conducted at a social science university. Therefore, the teachers may have had lower technological skills than in technical settings. The results of the study cannot be generalized without further research. Third, more qualitative data should be collected to explore online teaching and learning issues, including teachers' online class management, learners' self-regulation, and support for teachers and students in online education during troubled times.

\section{ACKNOWLEDGEMENT}

We would like to thank all the participants and Hanoi University for taking part in this study.

\section{REFERENCES}

Aguilera-Hermida, A. P., Quiroga-Garza, A., Gómez-Mendoza, S., Del Río Villanueva, C. A., Avolio Alecchi, B., \& Avci, D. (2021). Comparison of students' use and acceptance of emergency online learning due to COVID-19 in the USA, Mexico, Peru, and Turkey. Education and Information Technologies, 26(6), 6823-6845. https://doi.org/10.1007/s10639-021-10473-8

Allen, I. E., \& Seaman, J. (2015). Grade Level: Tracking Online Education in the United States. In Babson Survey Research Group. Babson Survey Research Group. https://eric.ed.gov/?id=ED572778

Ayu, M., \& Pratiwi, Z. F. (2021). The implementation of online learning in English language teaching during pandemic: The teachers' voice. Journal of Research on Language Education, 2(2), 93-99. https://doi.org/10.33365/jorle.v2i2.1316

Baloran, E. T. (2020). Knowledge, attitudes, anxiety, and coping strategies of students during COVID-19 pandemic. Journal of Loss and Trauma. 25(8), 635-642 https://doi.org/10.1080/15325024.2020.1769300

Cataudella, S., Carta, S. M., Mascia, M. L., Masala, C., Petretto, D. R., Agus, M., \& Penna, M. P. (2021). Teaching in times of the Covid-19 pandemic: A pilot study on teachers' self-esteem and self-efficacy in an Italian sample. International Journal of Environmental Research and Public Health, 18(15), 8211. https://doi.org/10.3390/ijerph18158211 
Cho, M.-H., \& Cho, Y. (2016). Online instructors' use of scaffolding strategies to promote interactions: A scale development study. International Review of Research in Open and Distributed Learning, 17(6), 108-120. https://doi.org/10.19173/irrodl.v17i6.2816

Daniel, S. J. (2020). Education and the Covid-19 Pandemic. Prospects, 49(2020), 91-96. https://doi.org/10.1007/s11125-020-09464-3

Davis, F. (1989). Perceived usefulness, perceived ease of use, and user acceptance of information technology. MIS Quarterly, 13(3), 319-340. https://doi.org/10.2307/249008

Dhawan, S. (2020). Online learning: A panacea in the time of Covid-19 crisis. Journal of Educational Technology Systems, 49(1), 5-22. https://doi.org/10.1177/0047239520934018

Hermanto, Y. B., \& Srimulyani, V. A. (2021). The challenges of online learning during the Covid-19 pandemic. Jurnal Pendidikan Dan Pengajaran, 54(1), 46. https://doi.org/10.23887/jpp.v54i1.29703

Kakkad, D. P. (2021). A study on perception of teachers for online teaching during Covid 19 pandemic. International Research Journal of Humanities and Interdisciplinary Studies, 2(6), 30-37. http://irjhis.com/paper/IRJHIS2106006.pdf

Kuo, Y.-C., Walker, A. E., Schroder, K. E., \& Belland, B. R. (2014). Interaction, Internet selfefficacy, and self-regulated learning as predictors of student satisfaction in online education courses. The Internet and Higher Education, 20(2013), 35-50.

Lahman, M. K. E., Rodriguez, K. L., Moses, L., Griffin, K. M., Mendoza, B. M., \& Yacoub, W. (2015). A rose by any other name is still a rose? Problematizing pseudonyms in research. Qualitative Inquiry, 21(5), 445-453. https://doi.org/10.1177/1077800415572391

Lapitan, L. DS., Tiangco, C. E., Sumalinog, D. A. G., Sabarillo, N. S., \& Diaz, J. M. (2021). An effective blended online teaching and learning strategy during the COVID-19 pandemic. Education for Chemical Engineers, 35, 116-131.

https://doi.org/10.1016/j.ece.2021.01.012

Lumsden, S. H. (2017). The relationship between teaching presence and online instructor satisfaction in an online teacher training program [unpublished master's thesis]. Macquarie University, Sydney, Australia.

Luu, T. M. V. (2022). Readiness for Online Learning: Learners' Comfort and Self-Directed Learning Ability. International Journal of TESOL \& Education, 2(1), 213-224. https://doi.org/10.54855/ijte.222113

Maheshwari, G. (2021). Factors Affecting Students' Intentions to Undertake Online Learning: An Empirical Study in Vietnam. Education and Information Technologies, 2021, 1-21. https://doi.org/10.1007/s10639-021-10465-8

Miles, M. B., Huberman, A. M., \& Saldaña, J. (2014). Qualitative data analysis: A methods sourcebook. Thousand Oaks, CA. Sage Publications.

Minh, H. (2020). Dạy - học trực tuyến: Cơ hội số hóa đào tạo đại học. Báo Đại đoàn kêt, 2020. http://daidoanket.vn/day--hoc-truc-tuyen-co-hoi-so-hoa-dao-tao-dai-hoc464343.html (accessed Apr. 25, 2020). [Online teaching-learning: Opportunity for digitalization of higher education. Solidarity Newspaper. In Vietnamese]. 
MOETa. (2020). The information and communications going along with education and training in preventing Covid-19. Retrieved from https://en.moet.gov.vn/news/Pages/events.aspx?ItemID=3933.

MOETb. (2020). Đại Học Tiên Phong Đẩy Mạnh Chuyển Đổi Số Giáo Dục [Universities pioneer in educational digitalization]. Retrieved from https://moet.gov.vn/tintuc/Pages/phong-chong-nCoV.aspx?ItemID=6615.

Moralista, R. B., \& Oducado, R. M. R. (2020). Faculty perception toward online education in higher education during the coronavirus disease 19 (COVID-19) pandemic. Retrieved from https://ssrn.com/abstract=3636438

Nambiar, D. (2020). The impact of online learning during COVID19: Students' and teachers' perspectives. International Journal of Indian Psychology, 8(2), 783-793. https://doi.org/10.25215/0802.094

Ngo, D. H.(2021). Perceptions of EFL tertiary students towards the correlation between elearning and learning engagement during the COVID-19 pandemic. International Journal of TESOL \& Education, 1(3), pp. 235-259. EOI. http://eoi.citefactor.org/10.11250/ijte.01.03.013

Pallant. (2011). SPSS survival manual: A step by step guide to data analysis using SPSS. Crows Nest, NSW: Allen \& Unwin.

Pham, H.-H., \& Ho, T.-T.-H. (2020). Toward a 'new normal' with e-learning in Vietnamese higher education during the post COVID-19 pandemic. Higher Education Research \& Development, 39(7), 1327-1331. https://doi.org/10.1080/07294360.2020.1823945

Pham, T. T. T. (2022). Navigating the Turbulent Time: A Qualitative Inquiry into Resilience among Vietnamese ESL Teachers during COVID-19. International Journal of TESOL \& Education, 2(1), 40-53. https://doi.org/10.54855/ijte2202013

Shenoy, V., Mahendher, S., \& Vijay, N. (2020). COVID-19 lockdown technology adaption, teaching, learning, student engagement and faculty experience. Mukt Shabd Journal, 9(4), 698-702.

Sobaih, A. E. E., Hasanein, A. M., \& Abu Elnasr, A. E. (2020). Responses to COVID-19 in higher education: Social media usage for sustaining formal academic communication in developing countries. Sustainability, 12(16), 2-18. https://doi.org/10.3390/su12166520

Talidong, K. J. B., \& Toquero, C. M. D. (2020). Philippine teachers' practices to deal with anxiety amid COVID-19. Journal of Loss and Trauma. 25(6-7), 573-579 https://doi.org/10.1080/15325024.2020.1759225

Teddlie, C., \& Tashakkori, A. (2009). Foundations of mixed methods research: Integrating quantitative and qualitative techniques in the social and behavioral sciences. Thousand Oaks, CA. Sage Publications.

Teng, M. F., \& Wu, J. G. (2021). Tea or tears: Online teaching during the COVID-19 pandemic. Journal of Education for Teaching, 47(2), 290-292. https://doi.org/10.1080/02607476.2021.1886834

Wingo, N. P., Ivankova, N. V., \& Moss, J. A. (2017). Faculty perceptions about teaching online: Exploring the literature using the technology acceptance model as an organizing framework. Online Learning, 21(1), 15-35. https://doi.org/10.10.24059/olj.v21i1.761 
Zaili, N., Moi, L. Y., Yusof, N. A., Hanfi, M. N., \& Suhaimi, M. H. (2019). The factors of satisfaction on e-learning usage among Universiti Malaysia Kelantan students. Journal of Information System and Technology Management, 4(11), 73-83.

\section{Biodata}

Thach Ngoc Pham is the Chairman of the Board of Trustees, Hanoi University, Vietnam. He has nearly 30 years of teaching English at different levels of study and in different environments: in class, online, on television and radio. Thach Ngoc Pham completed his Ph.D. at Victoria University, Melbourne, Australia early 2015. His strong interests are in using technologies for English language teaching and learning, university governance, educational knowledge management, educational material development and teacher training.

Hong Van Nghiem is the Dean of the Japanese Studies Department, Hanoi University, Vietnam. She has nearly 20 years of teaching Japanese at different levels at some language universities in Vietnam. She has chaired and participated in several major language-related projects of the Vietnamese Ministry of Education and Training, such as the National Foreign Language Project. Hong Van Nghiem completed her Master's Degree at Osaka University, Japan, in 2010 and her Doctoral Degree at the Vietnam Academy of Social Sciences in 2018. Van's strong interests are in linguistics, especially cognitive linguistics, teaching methods, and ICT application in language teaching. 